\title{
Dietary Intake Patterns and Nutritional Status of Food Secure and Insecure Women Garment Factory Workers in Bangladesh
}

\author{
Sadika Sharmin ${ }^{1,2}$, Noor Aman Hamid ${ }^{3} \&$ Wan Abdul Manan Bin Wan Muda ${ }^{2}$ \\ ${ }^{1}$ Department of Rural Sociology, Bangladesh Agricultural University, Bangladesh \\ ${ }^{2}$ Programme in Nutrition, School of Health Science, University Sains Malaysia, Malaysia \\ ${ }^{3}$ Deapartment of Community Medicine, School of Medical Science, University Sains Malaysia, Malaysia \\ Correspondence: Sadika Sharmin, Department of Rural Sociology, Bangladesh Agricultural University, \\ Bangladesh. E-mail: nivin_1983@yahoo.com
}

\author{
Received: August 10, 2019 Accepted: March 24, 2020 Online Published: March 29, 2020 \\ doi:10.5539/jfr.v9n3p1 \\ URL: https://doi.org/10.5539/jfr.v9n3p1
}

\begin{abstract}
Maintaining a good dietary intake and adequate nutritional status to ensure food security is a major challenge for the garment factory workers in Bangladesh. This study was carried out using a cross-sectional survey. To determine the nutritional status of the female garment factory workers', anthropometric measurements as calculating height, weight, body mass index (BMI), waist and hip circumference were conducted. Using a validated semi-quantitative food frequency questionnaire, the dietary intake patterns of female garment factory workers were assessed. In the cereal group, dried rice $(0.18$ (SD 0.38), $P=0.005$ ) was preferred most by food-insecure participants. A significant mean intake of lentil (1.43(SD 0.49), $P=0.020$ ) was observed by food-secure female garment factory workers. A higher percentage was noticed in the occurrence of obese (94.4), and unhealthy waist circumference (69.4) among food-insecure female garment factory workers. Children studying in the family (adjusted $\mathrm{b}=-0.20,95 \% \mathrm{CI},(-0.35,-0.04), P=0.013)$ was significantly associated with a decline in BMI of contributors in the study. Age (adjusted $b=0.30,95 \% \mathrm{CI}(0.15,0.44), P=<0.001)$ and physical function (adjusted $\mathrm{b}=-0.05,95 \% \mathrm{CI}(-0.11,-0.003), P=0.04)$ were significantly associated with the increase or decrease in waist circumference of women garment factory workers. Anthropometric measurements (weight, body mass index, waist circumference) of female garment factory workers should be checked regularly.
\end{abstract}

Keywords: Bangladesh, dietary intake, food secure, food insecure, garment, nutritional status, women

\section{Introduction}

For being in good health and increasing working capacity of women, adequate nutrition is important for them as well as for their offspring's health (Branca, Piwoz, Schultink \& Sullivan, 2015). Poor nutrition is associated with numerous poor health related outcome such as impaired cognition, reduced work capacity and impaired immune responses, leading to lowered resistance to infections (Black et al., 2013).

The garment industry in Bangladesh is the main export division and main source of foreign exchange for last 25 years. This industry provides job opportunity to around 4 million workers, most of whom are women (Emran, Kyriacou and Rogan, 2019). The highest and minimum salary division for garment workers are respectively 107 USD and 156 USD in Vietnam, 180 USD and 321 USD in the Philippines, 116 USD and 125 USD in Pakistan, 104 USD and 266 USD in Indonesia, 155 USD and 321 USD in China (http://shenglufashion2016.com). According to Bangladesh Ministry of Labour and Employment (2013), the current salary grades for garment workers in Bangladesh ranged between Tk. 5300 (68.46 US dollar) and Tk. 13000 (165.48 US dollar) on a monthly basis ( 1 US dollar $=78.48$ Taka). Female garment factory workers are the key wokers but their low payments make their life vulnerable. It also created malnutrition alongwith different health related problems. It was found that $43.33 \%$ were underweight $\left(\mathrm{BMI} \leq 18.5 \mathrm{~kg} / \mathrm{m}^{2}\right.$ ) and $53.67 \%$ had different medical issues (Hasnain et al., 2014). Majority of garment workers are adolscent girls, from 18-35 years old. Among them $41 \%$ were stunned, 17\% were wasted with high anemia levels. The main reasons behind nutritional anaemia in Bangladeshi garment workers are inadequte dietary intake of energy, protein and micronutrients (Akter, S. 2019). The earlier researchers found persistent low wages leads to excessive work and overtime which ultimately trapped into poverty and poor well being. It also results intake of inadequate food and poor health which affects their 
nutritional status. In earlier studies, the association of income with their food security and the link of food security with their dietary intake pattern and nutritional status was not investigated. But this study tries to assess the food security situation of female garment factory workers with their dietary intake pattern and nutritional situation.The objectives of the study was, therefore, to assess the dietary intake pattern and nutritional status of female garment factory workers as food secure or insecure group. How different socio-economic and socio-demographic variables affect their nutritional status were also studied. In this study, it has estimated that $2122 \mathrm{kcal} /$ day (Poverty line I means recommended intake eqauls $2122 \mathrm{kcal} / \mathrm{capita} / \mathrm{day}$ ) is the minimum energy requirement for food secure people (Nahar et al, 2013).

\section{Methodology}

\subsection{Study Design and Time}

A cross-sectional study was conducted in this survey. The data collection took a total of seven months, within the period between February, 2014 and August, 2014.

\subsection{Study Area}

The study was carried out in Dhaka and Gazipur in Bangladesh. These two cities are the major cities for the garment industries.

\subsection{Sample Size}

A single proportion formula was applied to figure the sample size for food insecure women garment factory workers: $(1.96 / \Delta)^{2} \mathrm{P}(1-\mathrm{P})$. The prevalence of food insecurity was 85.2 percent among the food insecure mothers in palm-plantation households, Negeri Sembilan, Malaysia (Mohamadpour, Sharif \& Keysami, 2012).

Ten events per variable is a widely adopted minimal criterion for performing binary logistic regression (Moons et al., 2015). The required sample size was calculated for logistic regression analysis was 451 .

The estimated sample size was calculated for the linear regression analysis was 154 based on the criterion on N=10k (Tabachnick \& Fidell, 2019).

Due to the limitation of time and resources, the researcher limited her sample size to 434 .

The present research used the records of garment factories located in Dhaka and Gazipur. Records were collected from BGMEA office, Dhaka. Non-probability sampling was used in selection of garment factories (Lucas, 2014). Three sections namely the finishing, quality control and sewing were purposively selected as these were the most female concentrated sectors. Twenty-two respondents from every sector were selected using the convenience sampling (Sauders, Lewis \& Thornhill, 2012).

\subsection{Instrument}

Measuring dietary intake pattern of food secure and insecure female garment factory workers, a validated semi-quantitative food frequency questionnaire was used. The FFQ was in English and it consisted of nine common food groups such as cereal, lentil, meat item, fish, egg, potato, vegetable, fruit and dairy product. The questionnaire was developed by Chen and his team (Chen, Ahsan, Parvez \& Howe, 2004). Adding some other food items, researcher pilot tested the questionnaire by herself. Most items were originated from Bangladesh, and the added items were biscuits in the cereal category, chicken and liver in the meat items category, all fish items and papaya in the fruit items category. The participants were reminded to consume their foods with their usual frequency of eating and drinking. The amount supplied for all the foodstuffs were requested, also as mentioned in the food frequency questionnaire.

Female garment factory workers' nutritional status were measured with anthropometric measurements. The measurements were done by measuring weight, height, body mass index, waist and hip circumference.

Apart from that, the basic characteristics of the respondents were also collected. The participants were asked about the socio-demographic and socio-economic status such as age, educational qualification, possessing physical assets, salary, bonus received, allowance for accommodation, medical allowance, compensation for work injury etc. Data on their working conditions such as working hours including overtime hours, getting casual leave, maternity leave, sick leave, enjoying public holidays, job satisfaction, experience of harassment, application of labour law, facilities of labour union etc. were also asked to the participants.

\subsection{Data Collection}

The total female workers in selected garment factories were 38,602. A total of 434 female garment factory workers aged 19-40 years were interviewed. Pregnant or breastfeeding female workers or workers who had health problems were excluded. 
Prior to the data gathering, the tools were endorsed by the University Human Ethics Committee from University Sains Malaysia. Recruited by convenience sampling, the process of the research was explained to the participants, and the consent forms were also obtained.

Measuring dietary intake pattern of women garment factory workers, the participants were asked to recall about recipes and methods of cooking. Locally used plates, cups and spoons were shown to the respondents to define the portion sizes during the interview. Each food item intake recorded in this FFQ was coded as no intake of specific food item once a day $=0$, food item intake once a day $=1$, twice a day $=2$, three times a day $=3$.

In anthropometric measurements, height was measured using the combined height-weight scale TZ-160 (China). Body mass index was calculated from the measured body weight $(\mathrm{kg})$ and height $\left(\mathrm{m}^{2}\right)$ (Nowak-Szczepanska, Gomula \& Koziel, 2019). The World Health Organization STEPwise protocol for measurement was used: waist circumference was calculated around the midpoint between the lower margin of the last palpable rib and the top of the iliac crest (World Health Organization, 2011).

\subsection{Statistical Analysis}

The collected data from this study were analyzed using Statistical Package for Social Sciences (SPSS) version 22.0. Descriptive statistics were used to check the missing data. Basic characteristics of respondents with anthropometric measurements and data collected through food frequency questionnaire were tested for normality. As the distributions of all variables were normal, parametric tests were performed. To describe the basic socio-demographic characteristics with their working condition, mean and frequency of the variables were calculated. Independent t-test was applied to distinguish the mean frequency of dietary intake of food secure and insecure female garment factory workers. To find out the association of nutritional status with food insecurity of women garment factory workers, chi-square analysis were performed. Linear regression was performed to assess for the significant associated factors correlated with body mass index and waist circumference (Dependent variable). Screening by simple linear regression, independent variables $(\mathrm{p}<0.25)$ were included in the multiple linear regression. Independent variables included were age, household size, number of children studying, good job satisfaction and physical function.

\subsection{Ethical Approval}

The study was approved by the Human Ethics Committee, University Sains Malaysia (USMKK/PPP/JEPem [265.3.(9)], and the Human Ethics Committee of the Faculty of Agricultural Economics and Rural Sociology, Bangladesh Agricultural University.

\section{Results}

A total number of 434 female garment factory workers participated in the study. The mean age of the participants was 29.32(SD 5.42) years. A majority (48.2 percent) of the participants were educated up to primary level while 42.6 and 9.2 percent of the respondents received education up to secondary and a higher level respectively. The mean household size was 4.77 (SD 0.85) person. Following the patriarchal family structure in Bangladesh, most participants' households in this study were male-headed ( 82.7 percent). Only 17.3 percent families were headed by mothers after the death of their husbands or divorced.

The income level of the workers ranged from Tk. 5400 (US dollar 68.81)-Tk. 13908 (US dollar 177.21) per month depending on the grade. The total income included basic income, overtime salary, allowances and bonuses (1 US dollar $=78.48$ Taka). A total of 62.4 percent of the participants had agriculture land in their own villages. The lands were cultivated by their family members. They got minimal support by getting crops and cereals from agriculture farming. Most female workers ( 95 percent) took part in overtime work. A total of 58.5 percent female garment factory workers were satisfied with their jobs while 41.5 percent workers were impartial (in the middle between satisfaction and dissatisfaction). The socio-demographic characteristics and working condition of women garment factory workers are presented in Table 1. 
Table 1. Socio-demographic characteristics of female garment factory workers with their working condition $(\mathrm{n}=434)$

\begin{tabular}{|c|c|c|}
\hline Variable & n (\%) & Mean(SD) \\
\hline Age (y) & & $29.32(5.42)$ \\
\hline $19-23$ & $69(15.9)$ & \\
\hline $24-28$ & $141(32.5)$ & \\
\hline $29-33$ & $119(27.4)$ & \\
\hline $34-38$ & $79(18.2)$ & \\
\hline$>38$ & $26(6.0)$ & \\
\hline \multicolumn{3}{|l|}{ Education level } \\
\hline Primary (I-V) & $209(48.2)$ & \\
\hline Secondary (VI-IX) & $185(42.6)$ & \\
\hline Higher secondary (X-XII) & $40(9.2)$ & \\
\hline Household size & & $4.77(0.85)$ \\
\hline $3-4$ & $162(37.3)$ & \\
\hline $5-6$ & $265(61.1)$ & \\
\hline$\geq 7$ & $7(1.6)$ & \\
\hline \multicolumn{3}{|l|}{ Head of household } \\
\hline Husband & $359(82.7)$ & \\
\hline Respondent & $75(17.3)$ & \\
\hline \multicolumn{3}{|l|}{ Agriculture farming } \\
\hline No & $163(37.6)$ & \\
\hline Yes & $271(62.4)$ & \\
\hline Women's total income (Tk.) & & $8502.57(1258.90)$ \\
\hline Tk.5000-Tk.7999 & $146(33.6)$ & \\
\hline Tk.8000-Tk.10999 & $267(61.5)$ & \\
\hline Tk.11000-Tk.13999 & $21(4.8)$ & \\
\hline \multicolumn{3}{|l|}{ Working Condition } \\
\hline \multicolumn{3}{|l|}{ Job satisfaction } \\
\hline Neutral & $180(41.5)$ & \\
\hline Good & $254(58.5)$ & \\
\hline \multicolumn{3}{|l|}{ Doing overtime } \\
\hline No & $22(5.1)$ & \\
\hline Yes & 412(94.9) & \\
\hline
\end{tabular}

1 US dollar $=78.48$ taka

In Table 2, the significant mean intake was higher for food insecure women in the consumption of dried rice (0.18(SD 0.38), $P=0.005)$ than food secure females. Food secure participants used more lentil in their daily serving (1.43(SD 0.49) than insecure ones (1.30(SD 0.46), $P=0.020$ ). A higher mean intake was observed for the consumption of beef among the food insecure adults (0.23(SD 0.42) servings per day). Chicken was consumed more by secure food participants. The mean intake was lower for fish items for food secure participants. No significant difference in the mean intake of chicken eggs between these two groups was observed. 
Table 2. Frequency of dietary intake of cereal, potato, lentil, meat, fish and egg between food secure and insecure group $(\mathrm{n}=434)$

\begin{tabular}{llll}
\hline Food group & Foodsecure mean(SD) & Foodinsecure mean(SD) & $\boldsymbol{P}$-value \\
\hline Cereals & & & \\
$\quad$ Steamed rice & $2.87(0.34)$ & $2.88(0.33)$ & 0.791 \\
$\quad$ Puffed rice & $0.12(0.33)$ & $0.16(0.37)$ & 0.268 \\
Dried rice & $0.08(0.28)$ & $0.18(0.38)$ & $0.005^{*}$ \\
$\quad$ Ruti & $0.43(0.50)$ & $0.43(0.50)$ & 0.903 \\
Potato & $0.79(0.98)$ & $0.98(1.00)$ & 0.067 \\
Lentil & $1.43(0.49)$ & $1.30(0.46)$ & $0.020^{*}$ \\
Meat items & & & \\
$\quad$ Beef & $0.16(0.37)$ & $0.23(0.42)$ & 0.107 \\
$\quad$ Chicken & $0.31(0.46)$ & $0.26(0.44)$ & 0.290 \\
Fish items & & & \\
$\quad$ Yellowtail Mullet & $0.20(0.40)$ & $0.21(0.40)$ & 0.937 \\
$\quad$ Olive Barb & $0.18(0.38)$ & $0.26(0.44)$ & 0.066 \\
Pangus & $0.24(0.44)$ & $0.19(0.39)$ & 0.277 \\
$\quad$ Tilapia & $0.19(0.39)$ & $0.23(0.42)$ & 0.325 \\
Hen egg & $0.38(0.48)$ & $0.39(0.48)$ & 0.789 \\
\hline
\end{tabular}

The nutritional status of the female garment factory workers in food secure and insecure categories is described in Table 3. Following the BMI classification for Asian people, higher percentage was observed in the obese (94.4) category followed by normal (72.6) and underweight (68.6) group among the food insecure participants (Garvey, Mechanick \& Brett, 2016). Similarly, 69.4 percent of food insecure women were at risk of waist circumference $(\geq 88 \mathrm{~cm}$.) and 30.6 percent were in the normal range $(<88 \mathrm{~cm}$.)

Table 3. Nutritional status of food secure and insecure women garment factory workers $(n=434)$

\begin{tabular}{|c|c|c|c|c|}
\hline Variables & Food secure (\%) & $(\mathrm{n}=122)$ & Food insecure (\%) $(\mathrm{n}=312)$ & P-value \\
\hline \multicolumn{5}{|l|}{ BMI classification (Asian) } \\
\hline Underweight $(<17.5)$ & $9.8(31.4)$ & & $25.2(68.6)$ & \multirow{4}{*}{0.12} \\
\hline Normal (17.5-22.9) & $73.9(27.4)$ & & 189.1(72.6) & \\
\hline Overweight (23-27.9) & $33.2(32.2)$ & & $84.4(67.8)$ & \\
\hline Obese $(\geq 28)$ & $5.1(5.6)$ & & $12.9(94.4)$ & \\
\hline \multicolumn{5}{|c|}{ WC classification (for women) } \\
\hline Normal $(<88 \mathrm{~cm})$ & $74.2(26.5)$ & & $189.8(73.5)$ & \multirow[t]{2}{*}{0.21} \\
\hline At risk $(\geq 88 \mathrm{~cm})$ & $47.8(30.6)$ & & $122.2(69.4)$ & \\
\hline
\end{tabular}

In Table 4, based on simple linear regression, the factors that were significantly associated with BMI were age $(P=<0.001)$, household size $(P=0.094)$, number of children studying $(P=0.049)$, good job satisfaction $(P=0.021)$ and physical function $(P=0.002)(P<0.25)$. The results from the multiple linear regression showed a significant and negative relationship between the BMI and the number of children studying, with adjusted $b=-0.20,95 \% \mathrm{CI}$, $(-0.35,-0.04), P=0.013$. One unit increase in the number of children who were still studying would decrease the BMI of the female garment factory workers by 0.20 units. $(P<0.05)$.

Table 4. Simple linear and multiple linear regression of factors associated with body mass index among female garment factory workers $(\mathrm{n}=434)$

\begin{tabular}{|c|c|c|c|c|c|}
\hline \multirow[t]{2}{*}{ Variable } & \multicolumn{2}{|c|}{ Simple Linear Regression } & \multicolumn{3}{|c|}{ Multiple Linear Regression } \\
\hline & $b(95 \% \mathrm{CI})$ & $P$-value & Adjusted $b(95 \%$ CI $)$ & $t$ statistics & $P$-value \\
\hline Age & $0.09(0.04,0.15)$ & $<0.001$ & - & - & - \\
\hline Household size & $-0.29(-0.64,0.05)$ & 0.094 & - & - & - \\
\hline No. of children studying & $0.32(0.001,0.64)$ & 0.049 & $-0.20(-0.35,-0.04)$ & -2.50 & 0.013 \\
\hline Good job satisfaction & $0.70(0.10,1.30)$ & 0.021 & - & - & - \\
\hline Physical function & $-0.03(-0.05,-0.01)$ & 0.002 & - & - & - \\
\hline
\end{tabular}

In Table 5, based on the univariate analysis, independent variables that were significantly associated $(P<0.25)$ 
with the waist circumference of the respondents were age $(P=<0.001)$, household size $(P=0.026)$ and physical function $(P=0.003)$. After conducting the multiple linear regression, a significant relationship was found between the waist circumference with age, with adjusted $\mathrm{b}=0.30,95 \% \mathrm{CI}(0.15,0.44), P=<0.001$. One year increase in the age of the participants would increase their waist circumference by 0.30 units. A significant relationship was also found between waist circumference and physical function of the respondents, with the adjusted $\mathrm{b}=-0.05,95 \% \mathrm{CI}$ $(-0.11,-0.003), P=0.04$. One score increase in physical function scale of the participants would decrease their waist circumference by 0.05 units.

Table 5. Simple linear and multiple linear regression of factors associated with waist circumference among female garment factory workers $(n=434)$

\begin{tabular}{|c|c|c|c|c|c|}
\hline \multirow[t]{2}{*}{ Variable } & \multicolumn{2}{|c|}{ Simple Linear Regression } & \multicolumn{3}{|c|}{ Multiple Linear Regression } \\
\hline & $b(95 \% \mathrm{CI})$ & $P$-value & Adjusted $b(95 \%$ CI $)$ & $t$ statistics & $P$-value \\
\hline Age & $0.36(0.21,0.50)$ & $<0.001$ & $0.30(0.15,0.44)$ & 4.0 & $<0.001$ \\
\hline Household size & $-1.06(-2.00,-0.12)$ & 0.026 & - & - & - \\
\hline Physical function & $-0.08(-0.14,-0.03)$ & 0.003 & $-0.05(-0.11,-0.003)$ & -2.06 & 0.04 \\
\hline
\end{tabular}

\section{Discussion}

Cereals are categorized as calorie foods, and food insecure respondents appeared to prefer them more. Significantly higher intake of dried rice was observed among food insecure female garment factory workers. Dharma et al., (2013) found that low-income individuals tend to buy low cost, more calorie dense foods. Their diets were based on energy-dense foods tend to be high in processed staples as refined grains. Significant mean intake of lentil was higher for food secure female garment factory workers as noticed in this study. Usually, poor people in Bangladesh consume lentil almost daily as a protein-rich food alternative to meat or fish. Arsenault et al., (2013) found that 64 percent of female in rural areas of Bangladesh consumed lentil once a day in their regular dietary intake. Most of the food insecure female workers chose beef and fish as their preferred items for their dietary intake was found in this study. Taste preference was considered in intake of these foods. Otherwise, Beef and fish were served in the canteen of the investigated garment factories twice or more in a week. Food insecure workers consumed the foods in the canteen. They did not eat chicken regularly in their daily dietary intake. They took beef/ fish as main protein item which was served in the canteen. So, their mean intake was higher in consumption of beef and fish. Food secure workers preferred chicken in their regular dietary intake compared beef or fish. So, their mean intake was higher for consumption of chicken.

A high proportion of obese (BMI $\geq 28 \mathrm{~kg} / \mathrm{m}^{2}$ ) and at risk waist circumference ( $\geq 88 \mathrm{~cm}$ ) were marked among food insecure female garment factory workers. Highlighting the danger of obesity for food insecure female may correspond to the direct outcome of their diet. Food insecure households have to limit their purchase of a variety of food for consumption. It results in the consumption of high energy but low-cost foods. Similar findings were found by Gooding, Walls \& Richmond (2012) that food insecure women had a BMI that was on average 0.9 $\mathrm{kg} / \mathrm{m}^{2}$ units higher than women who were food secure.

Number of children studying in the school was significantly associated for decrease in respondents' BMI. Raising a number of children who are still studying forces the workers to earn more and do extra overtime hours. The extra physical activity reduced BMI. Female who moved a lot in their daily physical activities, reduced their BMI in the range of 0.24-0.28 points (Sarma et al., 2014).

Age was found as a significant associated factor for the increase in waist circumference of the female garment factory workers. Waist increases as one became older and it affected both male and female (Stevens, Katz \& Huxley, 2010). Increasing age was associated with higher overweight and obesity risk among both rural and urban Bangladeshi women residents (Chowdury, Adnan \& Hasan, 2018). Increasing physical function was found as a significant associated factor for decreasing waist circumference of the female garment factory workers. Studies (Golubic et al., 2015; May et al., 2010; Hamer et al., 2013) found that sensible and forceful bodily actions had an alliance with the lessening in waist circumference.

\section{Conclusion}

A significant difference was observed between food secure and insecure female garment factory workers in intake of dried rice and lentil. Assessing the nutritional status of food secure and insecure female garment factory workers, it was found that 94.4 percent food insecure participants fall in the category of obese class $\left(\geq 28 \mathrm{~kg} / \mathrm{m}^{2}\right)$ while the percentage was only 5.6 percent for food secure participants. The percentage difference of food secure and insecure participants for at risk $(\geq 88 \mathrm{~cm})$ waist circumference classification was also very high $(30.6 \%$ for 
food secure; $69.4 \%$ for food insecure). The number of children studying in a family was significantly and negatively associated with decreasing BMI of female garment factory workers. With multiple linear regression, age and physical function were found significantly associated with enlarge or reduce waist circumference. The factory authority can start regular weight/BMI/waist circumference checking especially for female workers (Roberto et al., 2014).

\section{Conflict of Interest}

The authors declare that they have no significant financial, professional or personal interests that might have influenced the performance or presentation of the work described in this manuscript.

\section{Acknowledgements}

The authors would like to thank University Sains Malaysia and USM fellowship for approving and supporting this study. Also, admiration is extended to the authorities of garment industries for allowing the researchers to administer the study.

\section{Author Contributions}

Sadika Sharmin collected the data, analysed it and developed the manuscript. All the authors revised the manuscript.

\section{References}

Akter, S. (2019). Health and Nutritional Status of Female Garment Workers in Bangladesh, Conference Paper, presented at International Nutrition in Germany.

Arsenault, J. E., Yakes, E. A., Islam, M. M., Hossain, M. B., Ahmed, T., ... Brown, K. H. (2013). Very low adequacy of micronutrient intakes by young children and women in rural Bangladesh is primarily explained by low food intake and limited diversity. The Journal of Nutrition, 143(2), 197-203. https://doi.org/10.3945/jn.112.169524

Black, R. E., Victora, C. G., Walker, S. P., Bhutta, Z. A., Christian, P., \& Martorell, R. (2013). Maternal and child under nutrition and overweight in low-income and middle-income countries. Lancet, 382, 427-451. https://doi.org/10.1016/S0140-6736(13)60937-X

Branca, F., Piwoz, E., Schultink, W., \& Sullivan, L. M. (2015). Nutrition and health in women, children and adolescent girls. BMJ, 351. https://doi.org/10.1136/bmj.h4173

Chen, Y., Ahsan, H., Parvez, F., \& Howe, G. R. (2004). Validity of a food-frequency questionnaire for a large prospective cohort study in Bangladesh. Br J Nutr, 92(5), 851-859. https://doi.org/10.1079/BJN20041277

Chowdhury, M. A. B., Adnan, M. M., \& Hassan, M. Z. (2018). Trends, prevalence and risk factors of overweight and obesity among women of reproductive age in Bangladesh: a pooled analysis of five national cross-sectional surveys. BMJ Open, 8, e018468. https://doi.org/10.1136/bmjopen-2017-018468

Dharma, E. C., Andreina, M -F, B. A., Karen, S., Rodolfo, R. V., \& Enrique, C. A. (2013). Food Purchasing Selection Among Low-income, Spanish-speaking Latinos. Am J Prev Med, 44(3), S267-S273. https://doi.org/10.1016/j.amepre.2012.11.012

Emran, S. N., Kyriacou, J., \& Rogan, S. (2019). New Oxfam report reveals the suffering of female garment workers in Bangladesh \& Vietnam. Retrieved from https://zerrin.com/blogs/read/oxfam-report-australian-fashion-brands-poor-conditions-garment-workers

Garvey, W. T., Mechanick, J. I., \& Brett, E. M. (2016). American Association of Clinical Endocrinologists and American College of Endocrinology comprehensive clinical practice guidelines for medical care of patients with obesity. Endocr Pract., 22(suppl 3), 1-203. https://doi.org/10.4158/EP161365.GL

Golubic, R., Wijndaele, K., Sharp, S. J., Simmons, R. K., Griffin, S. J., Wareham, N. J., Ekelund, U., \& Brage, S. (2015). Physical activity, sedentary time and gain in overall and central body fat: 7-year follow-up of the ProActive trial cohort. IJO, 39(1), 142-148. https://doi.org/10.1038/ijo.2014.66

Gooding, H. C., Walls, C. E., \& Richmond, T. K. (2012). Food insecurity and increased BMI in young adult women. Obes (Silver Spring), 20(9), 1896-1901. https://doi.org/10.1038/oby.2011.233

Hamer, M., Brunner, E., Bell, J., Batty, G. D., Shipley, M., Akbaraly, T., Singh-Manoux, A., \& Kivimaki, M. (2013). Physical activity patterns over 10 years in relation to body mass index and waist circumference: the Whitehall II cohort study. Obesity, 21(12), E755-E761. https://doi.org/10.1002/oby.20446

Hasnain, G., Akter, M., Sharafat, S. I., \& Mahmuda, A. (2014). Morbidity patterns, nutritional status, and 
healthcare-seeking behavior of female garment workers in Bangladesh. Electron. Physician, 6(2), 801-807.

Lucas, S. R. (2014). Beyond the existence proof: ontological conditions, epistemological implications, and in-depth interview research. Qual \& Quant, 48(1), 387-408. https://doi.org/10.1007/s11135-012-9775-3

May, A. M., Bueno-de-Mesquita, H. B., Boshuizen, H., Spijkerman, A. M., Peeters, P. H., \& Verschuren, W. M. (2010). Effect of change in physical activity on body fatness over a 10-y period in the Doetinchem Cohort Study. AJCN, 92(3), 491-499. https://doi.org/10.3945/ajcn.2010.29404

Ministry of Labour and Employment (2013). Bangladesh Gazette. Dhaka: Bangladesh Government Press.

Mohamadpour, M., Sharif, Z. M., \& Keysami, M. A. (2012). Food insecurity, health and nutritional status among sample of palm-plantation households in Malaysia. JHPN, 30(3), 291-302. https://doi.org/10.3329/jhpn.v30i3.12292

Moons, K. G. M., Altman, D. G., Reitsma, J. B., Ioannidis, J. P., Macaskill, P., Steyerberg, E. W., \& Collins, G. S. (2015). Transparent Reporting of a multivariable prediction model for Individual Prognosis Or Diagnosis (TRIPOD): Explanation and Elaboration. Ann Int Med, 162(1), W1-W73. https://doi.org/10.7326/M14-0698

Nahar, Q., Choudury, S., Faruque, M. O., Sultana, S. S. S., \& Siddiquee, M. A. (2013). Desirable Dietary Pattern for Bangladesh. Workshop on Research to Inform Food and Nutrition Security Policies, Dhaka.

Nowak-Szczepanska, N., Gomula, A., \& Koziel, S. (2019). Mid-upper arm circumference and body mass index as different screening tools of nutritional and weight status in Polish school children across socio-political changes. SciRep, 9(12399). https://doi.org/10.1038/s41598-019-48843-5

Roberto, C., Hamid, E. B., Philipp, D., Gianluigi, C., \& Noureddin, D. (2014). Food System Sustainability and Food Security: Connecting the Dots. J. Food Secur, 2(1), 13-22.

Sarma, S., Zaric, G. S., Campbell, M. K., \& Gilliland, J. (2014). The effect of physical activity on adult obesity: Evidence from the Canadian NPHS panel. ECON HUM BIOL, 14, 1-21. https://doi.org/10.1016/j.ehb.2014.03.002

Sauders, M., Lewis, P., \& Thornhill, A. (2012). Research Methods for Business Students (Sixth Edition). Pearson Custom Publishing, New York.

Sheng, L. (2016). Minimum Wage in the Apparel Industry Continues to Rise in Most Asian Countries in 2016. http://shenglufashion2016.com

Stevens, J., Katz, E. G., \& Huxley, R. R. (2010). Associations between gender, age and waist circumference. Eur J Clin Nutr, 64(1), 6-15. https://doi.org/10.1038/ejen.2009.101

Tabach, B. G., \& Fidell, L. S. (2019). Using Multivariate Statistics (Seventh edition). Pearson Education: Boston.

World Health Organization (2011). Waist Circumference and waist-hip Ratio: report of a WHO expert consultation, Geneva.

\section{Copyrights}

Copyright for this article is retained by the author(s), with first publication rights granted to the journal.

This is an open-access article distributed under the terms and conditions of the Creative Commons Attribution license (http://creativecommons.org/licenses/by/4.0/). 